\title{
Tracking the response of biodiversity patterns through deep time to changes in environments
}

\author{
DOMINIC STEMMLER ${ }^{1}$, TARAS GERYA ${ }^{1}$, LOÏC \\ PELLISSIER $^{1}$ AND ROBERT J. STERN ${ }^{2}$
}

${ }^{1}$ ETH Zurich

${ }^{2}$ University of Texas at Dallas

Presenting Author: dominic.stemmler@erdw.ethz.ch

The evolution of species, atmosphere and oceans is intrinsically linked to the dynamics of the lithosphere, and therefore, to Earth's landscape, climate and nutrient supply.

We use deep time plate reconstructions $[1,2]$ coupled to different hypothetical climate scenarios by using fast general circulation models approximating a period from $540 \mathrm{Ma}$ to present. Using gen3sis [3], an eco-evolutionary biodiversity model, we simulate and investigate emerging biodiversity patterns as a result of geology and climate over this long time span. By varying the earth dynamics, including the movement of continents, atmospheric composition as well as biological parameters including for multiple simulation runs, we investigate causal connections between these different domains.

With more realistic regional geodynamic experiments by I3ELVIS [4], a 3D thermo-mechanical viscoplastic geodynamical model, we can supplement global hypothetical climate scenarios by simulating the release of greenhouse gasses of big degassing events such as the P-T eruption of the Siberian traps. Combining these models and reconstructions and analyzing the results, we develop a new methodology for understanding the feedback loops between geodynamics, climate and life evolution.

Ultimately we would like to apply our models to important events in Earth's history like supercontinent formation, breakup and large igneous province eruptions.

This project is funded by Fond national suisse FNS: 192296

[1] Scotese, C.R., 2016. PALEOMAP PaleoAtlas for GPlates and the PaleoData Plotter Program, PALEOMAP Project, http://www.earthbyte.org/paleomap-paleoatlas-for-gplates/

[2] Merdith, A. S., Williams, S. E., Collins, A. S., Tetley, M. G., Mulder, J. A., Blades, M. L., Young, A., Armistead, S. E., Cannon, J., Zahirovic, S., \& Müller, R. D. (2021). Extending full-plate tectonic models into deep time: Linking the Neoproterozoic and the Phanerozoic. Earth-Science Reviews, 214, 103477. https://doi.org/10.1016/j.earscirev.2020.103477

[3] Oskar Hagen, Benjamin Flueck, Fabian Fopp, Juliano S. Cabral, Florian Hartig, Mikael Pontarp, Thiago F. Rangel and Loïc Pellissier (2020). gen3sis: General Engine for EcoEvolutionary Simulations. $\mathrm{R}$ package version 1.1 . https://CRAN.R-project.org/package=gen3sis

[4] Taras V. Gerya and David A. Yuen. Robust characteristics method for modelling multiphase visco-elasto-plastic thermomechanical problems. Physics of the Earth and Planetary Interiors, 163(1-4):83-105, August 2007 